\title{
PRODUCTION ENGINEERING ARCHIVES
}

\section{Investigation of tribological properties of CarbonX coating deposited on 100Cr6 steel}

\author{
Martin Vicen ${ }^{1}$, Jozef Bronček ${ }^{1}$, František Nový ${ }^{1}$ \\ ${ }^{1}$ University of Zilina, Univerzitna 1, 01026 Zilina, Slovakia, e-mail: martin.vicen@fstroj.uniza.sk
}

\begin{tabular}{l} 
Article history \\
Received 23.09.2019 \\
Accepted 15.11.2019 \\
Available online 09.12 .2019 \\
\hline Keywords \\
tribology \\
DLC coating \\
100Cr6 steel \\
friction
\end{tabular}

\begin{abstract}
The article deals with a reduction of friction coefficient of bearing steel 100Cr6. Reduction of friction was achieved by means of a CarbonX DLC coating. The coating exhibited excellent friction and mechanical properties. This coating was applied to samples made of $100 \mathrm{Cr} 6$ bearing steel. The friction results of the CarbonX coating were compared to the friction results of the $100 \mathrm{Cr} 6$ bearing steel. Reducing the friction of $100 \mathrm{Cr} 6$ bearing steel resulted in reduced wear and increase lifetime. The friction process of the samples will take place in an environment without lubrication. The aim of the article is to verify the behaviour of the DLC coating without the presence of lubricant in the friction node. The achieved results are to be interpreted in the conclusion of article.
\end{abstract}

\section{Introduction}

Most of the degradation mechanisms are initiated and propagated by defects occurring on the surface of components. For this reason, the formation of various surface layers is important to increase the durability and operational safety of components. Coatings can be applied for various reasons, such as increasing wear resistance, corrosion resistance, forming a thermal barrier, etc. (Pastorek et al., 2016, Ulewicz and Mazur, 2013). It is anticipated that application of CarbonX coating to the surface of $100 \mathrm{Cr} 6$ bearing steel will increase the performance of the components. In this way, the degradation process of the wear is eliminated or delayed, and the friction of the component is reduced (Brezničan et al., 2013).

The CarbonX coating is produced by a PVD technology (a physical way of coating in a vacuum) (Holleck and Schier, 1995). In this process, small coating thickness is obtained by means of physical principles. Physical coating methods are carried out at relatively low temperatures in the range of 200 ${ }^{\circ} \mathrm{C}$ to $500{ }^{\circ} \mathrm{C}$. This range of temperatures does not significantly affect the substrate of the material (Radek et al., 2018).

\section{Experimental}

The experimental part deals with tribological properties of heat-treated steel $100 \mathrm{Cr} 6$ with and without coating. Experiments were performed to determine and compare the coeffi- cient of friction between the quenched bearing steel - steel and quenched bearing steel - CarbonX coating at different loads $(4.9 \mathrm{~N} ; 9.8 \mathrm{~N}$ and $14.7 \mathrm{~N})$. The work describes the influence of temperature during the deposition of PVD coating on the mechanical properties of heat-treated bearing steel 100Cr6 (Radek et al., 2018).

The experimental material is a bearing steel 100Cr6 with the chemical composition shown in Table 1. The 100Cr6 steel is mainly used for production of bearing rings and bearing elements for rolling bearings. Due to the high requirements for wear and fatigue resistance, bearing steels are very complicated for production and heat treatment (Fabian et al., 2017, Liščić et al., 2010).

Table 1. Chemical composition of $100 \mathrm{Cr} 6$ steel (wt. \%)

\begin{tabular}{|c|c|c|c|}
\hline $\mathbf{C}$ & $\mathbf{S i}$ & $\mathbf{M n}$ & $\mathbf{P}$ \\
\hline 1.05 & 0.35 & 0.45 & 0.0029 \\
\hline $\mathbf{S}$ & $\mathbf{C r}$ & $\mathbf{N i}$ & $\mathbf{C u}$ \\
\hline 0.0033 & 1.55 & 0.182 & 0.170 \\
\hline $\mathbf{M o}$ & $\mathbf{A l}$ & $\mathbf{C o}$ & $\mathbf{F e}$ \\
\hline 0.072 & 0.030 & 0.01 & balance \\
\hline
\end{tabular}

The shape and dimensions of the test sample are shown in Figure 1. The geometry and dimensions of the samples were selected according to the requirements of the T-01M test tribometer on which tribological tests were performed. The samples have the shape of a circular disk. The CarbonX coating was created by method of magnetron sputtering on 
front side of the disc. The number of samples (discs) produced and subsequently tested was 4 (Liščić et al., 2010).

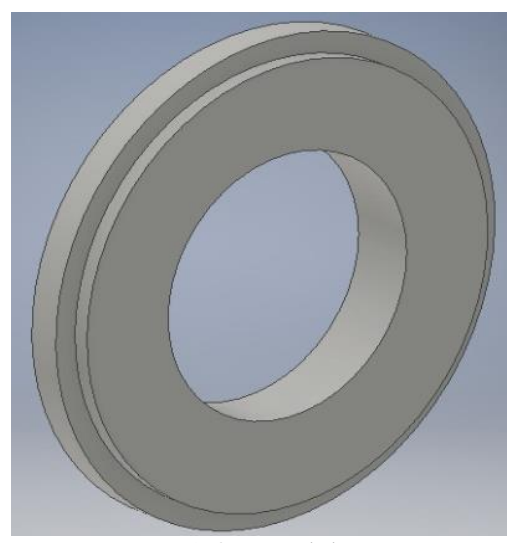

a) 3D model

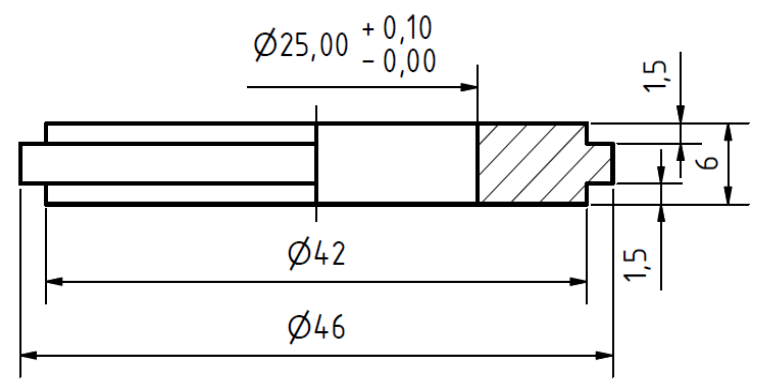

b) dimensions

Fig. 1. Test sample (Vicen et al., 2019)

\subsection{Tribology test}

Tribological test is based on the Ball-on-Disc method which is a standard method for testing the tribological properties of materials. The main part of the rotary micro tribometer is a tribological pair consisting of a ball (fixed at the end of the holder) and a sample that has the shape of a circular disk. The ball is made of standard 100Cr6 bearing steel with a diameter of $d=6 \mathrm{~mm}$. The hardness of ball is 750 $\mathrm{HV}$. The ball motion was uniform and rotary speed was $\mathrm{v}=$ $0.8 \mathrm{~m} / \mathrm{s}^{1}$. The principle of the test is that load is affecting the ball and the sample with DLC coating at the same time. A normal load consisted of a set of weights which create the normal force $F_{N}$ for load values $F_{N}=4.9 \mathrm{~N}, F_{N}=9.8 \mathrm{~N}$ and $\mathrm{F}_{\mathrm{N}}=14.7 \mathrm{~N}$. The friction force $\mathrm{F}_{\mathrm{T}}$ was determined by tensometric measurement of the disk position. Duration of the test is $t=5000 \mathrm{~s}$. Friction coefficient values were determined using the software and known values of $F_{T}$ and $F_{N}$. The principle of the method is shown in Figure 2.

Tribological tests were performed on a special testing device T-01M for evaluation of friction and wear resistance of structural materials (Figure 3).

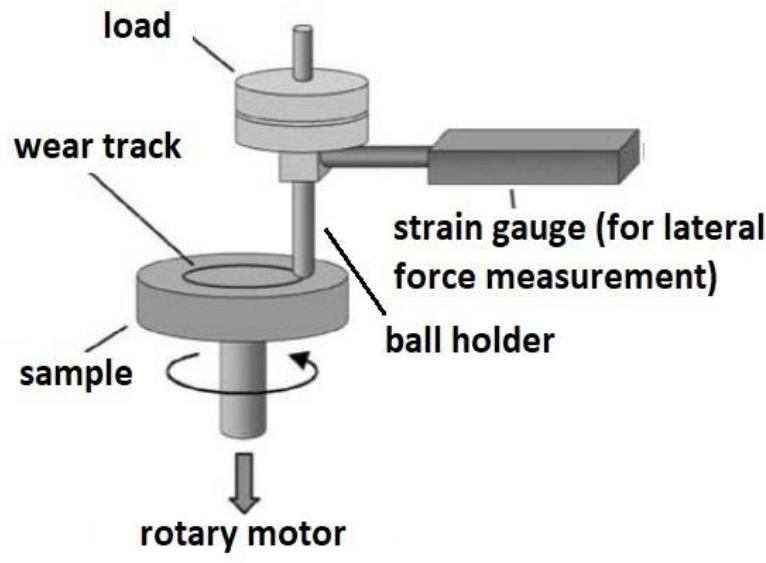

Fig. 2. Principle of Ball-on-Disc method

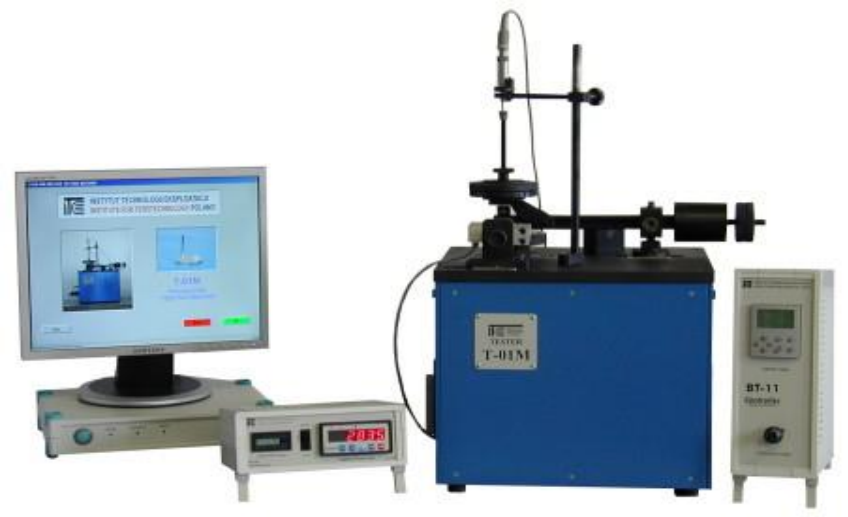

Fig. 3. Testing equipment T-01M (Radek et al., 2018)

\subsection{Evaluation of hardness}

The samples made from $100 \mathrm{Cr} 6$ bearing steel were heat treated by the conventional mode characteristic for this type of steel. Rockwell hardness was measured on all samples after heat treatment. The results are shown in Table 4. After the PVD coating process, hardness was measured on coated samples. The aim of the measurement was to verify the effect of the PVD coating temperature $\left(240{ }^{\circ} \mathrm{C}\right)$ on hardness of material substrate. The results are shown in Table 5.

\subsection{CarbonX coating}

CarbonX is the new low-friction a-C:H based DLC coating. Due its hardness, this coating is the right choice for applications where high abrasive wear occurs and softer lowfriction coatings reach their limits. The usage of CarbonX also efficiently reduces adhesions on components. The systematic build-up of layers combines multiple advantages of an a-C:H coating to ensure trouble-free tool performance, even under hard conditions (Drabik et al., 2018, Tsui and Garzon, 2017). 


\section{Results and discussion}

The results of the experiment consist of evaluation of friction coefficient of material pairs, evaluation of hardness and metallographic evaluation of coating.

\subsection{Evaluation of friction coefficient}

The tribological system consists of two parts. The first member is a hardened bearing ball with a diameter of $6 \mathrm{~mm}$ and a hardness of $65 \mathrm{HRC}$ and the second member is a test sample. Measured mean values of friction coefficients for individual tested loads are documented in Table 2 and Table 3. The results of the friction coefficients are shown in Figures 4, 5 and 6 .

Table 2. Friction coefficient of quenched bearing steel - steel

\begin{tabular}{|c|c|c|c|c|}
\hline \multirow{2}{*}{$\begin{array}{c}\text { Load } \\
{[\mathrm{N}]}\end{array}$} & \multicolumn{2}{|c|}{ Coefficient of friction [-] } & Average coefficient of \\
\cline { 2 - 4 } & $1 \mathrm{a}$ & $1 \mathrm{~b}$ & $2 \mathrm{a}$ & friction $[-]$ \\
\hline 4.9 & 0.907 & 0.809 & 0.850 & 0.855 \\
\hline 9.8 & 0.958 & 0.651 & 0.794 & 0.801 \\
\hline 14.7 & 0.754 & 0.746 & 0.725 & 0.742 \\
\hline \multicolumn{3}{|c|}{ Total friction coefficietn } & 0.8 \\
\hline
\end{tabular}

Table 3. Friction coefficient of quenched bearing steel - CarbonX

\begin{tabular}{|c|c|c|c|c|}
\hline \multirow{2}{*}{$\begin{array}{c}\text { Load } \\
{[\mathrm{N}]}\end{array}$} & \multicolumn{2}{|c|}{ Coefficient of friction [-] } & Average coefficient of \\
\cline { 2 - 4 } & $3 \mathrm{a}$ & $3 \mathrm{~b}$ & $4 \mathrm{a}$ & 0.223 \\
\hline 4.9 & 0.26 & 0.19 & 0.22 & 0.310 \\
\hline 9.8 & 0.338 & 0.242 & 0.349 & 0.246 \\
\hline 14.7 & 0.23 & 0.265 & 0.243 & 0.26 \\
\hline
\end{tabular}

Coated samples reached better friction values than uncoated samples. The friction coefficient results of the material pair quenched bearing steel - CarbonX coating are 3 times lower compared to quenched bearing steel - steel. Better results were obtained with all three loads tested. The CarbonX DLC coating deposited on 100Cr6 bearing steel substrate significantly improved friction properties. Friction results were obtained in the absence of lubricant which means that the coating exhibits good dry friction properties.

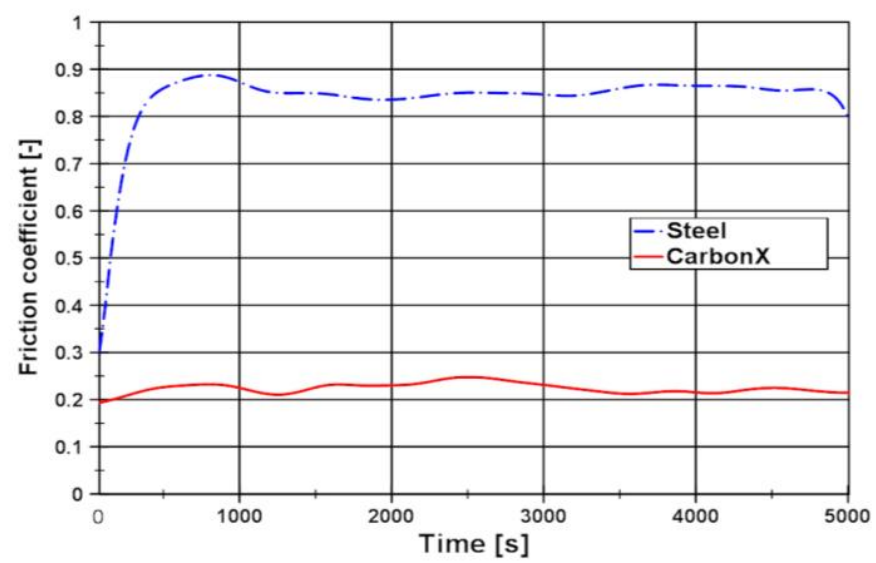

Fig. 4. Coefficient of friction, load $F_{N}=4.9 \mathrm{~N}$

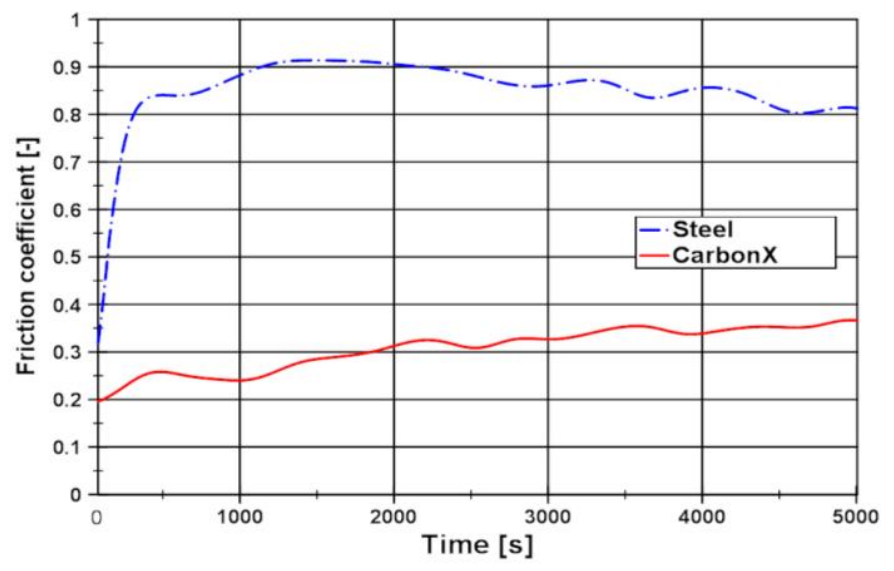

Fig. 5. Coefficient of friction, load $F_{N}=9.8 \mathrm{~N}$

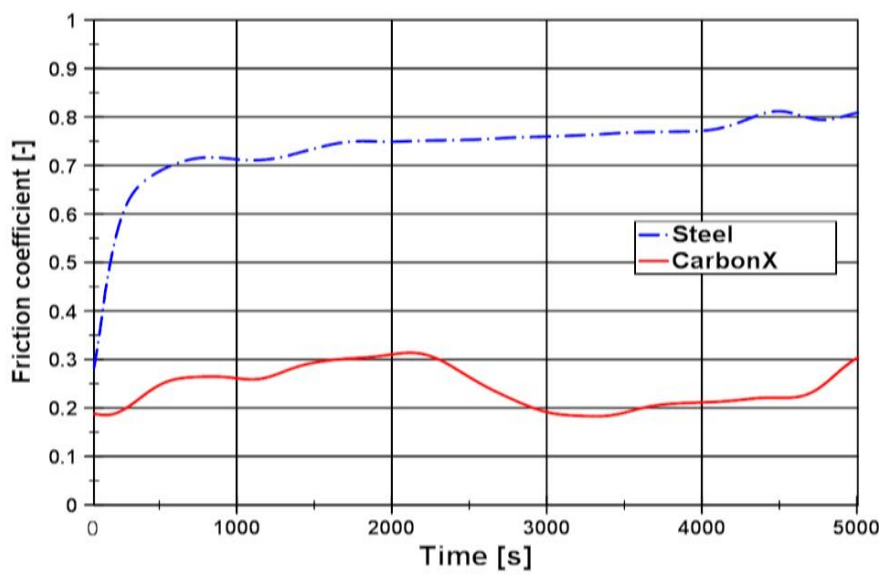

Fig. 6. Coefficient of friction, load $F_{N}=14.7 \mathrm{~N}$

\subsection{Evaluation of hardness}

The hardness results of samples after the heat treatment are shown in Table 4. Average hardness of samples was 63 HRC. Hardness of samples decreased after PVD coating. The average hardness was $59 \mathrm{HRC}$. Samples were coated at temperature of $240{ }^{\circ} \mathrm{C}$. This temperature caused a substrate hardness decrease of $4 \mathrm{HRC}$. Hardness of both materials fulfils the normative conditions for bearing steels. CarbonX coating shows significantly better friction properties than hardened 100Cr6 bearing steel with a hardness of $63 \mathrm{HRC}$.

Table 4. Hardness measurement after heat treatment

\begin{tabular}{|c|c|c|c|c|c|}
\hline \multirow{2}{*}{$\begin{array}{c}\text { Nr. } \\
\text { sample }\end{array}$} & \multicolumn{4}{|c|}{ Measurement number } & Average \\
\cline { 2 - 5 } & 1 & 2 & 3 & 4 & hardness \\
\hline 1 & 63 & 63 & 63 & 63 & 63 \\
\hline 2 & 63 & 63 & 63 & 62 & 63 \\
\hline 3 & 63 & 62 & 63 & 63 & 63 \\
\hline 4 & 62 & 63 & 63 & 63 & 63 \\
\hline
\end{tabular}

Table 5. Hardness measurement after PVD coating process

\begin{tabular}{|c|c|c|c|c|c|}
\hline \multirow{2}{*}{$\begin{array}{c}\text { Nr. } \\
\text { sample }\end{array}$} & \multicolumn{4}{|c|}{ Measurement number } & \multirow{2}{*}{$\begin{array}{c}\text { Average } \\
\text { hardness }\end{array}$} \\
\cline { 2 - 5 } & 1 & 2 & 3 & 4 & 59 \\
\hline 1 & 59 & 59 & 58 & 59 & 59 \\
\hline 2 & 58 & 59 & 59 & 59 & 5 \\
\hline
\end{tabular}




\subsection{Metallographic evaluation of coating}

The CarbonX DLC coating is shown in Figure 7. The coating thickness is about $1.5 \mu \mathrm{m}$. This is a very thin coating that adheres to the surface of 100Cr6 bearing steel (Figure 7b). It is very important that the coating has good adhesion properties for proper function.

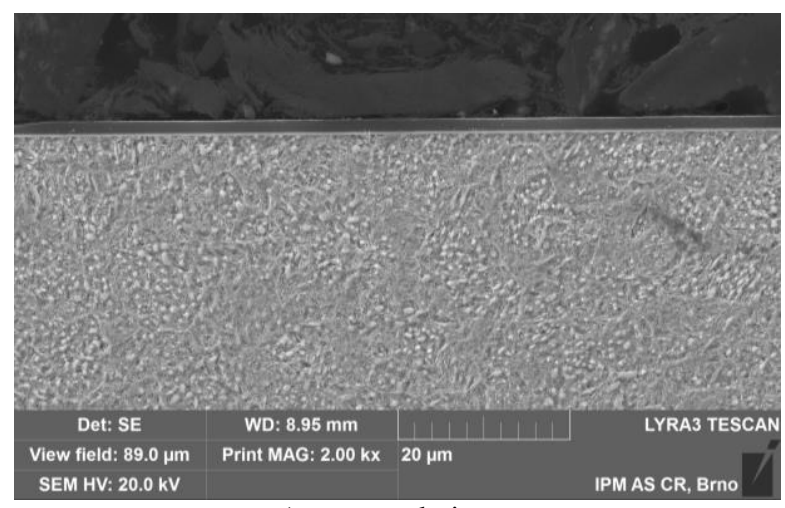

a) general view

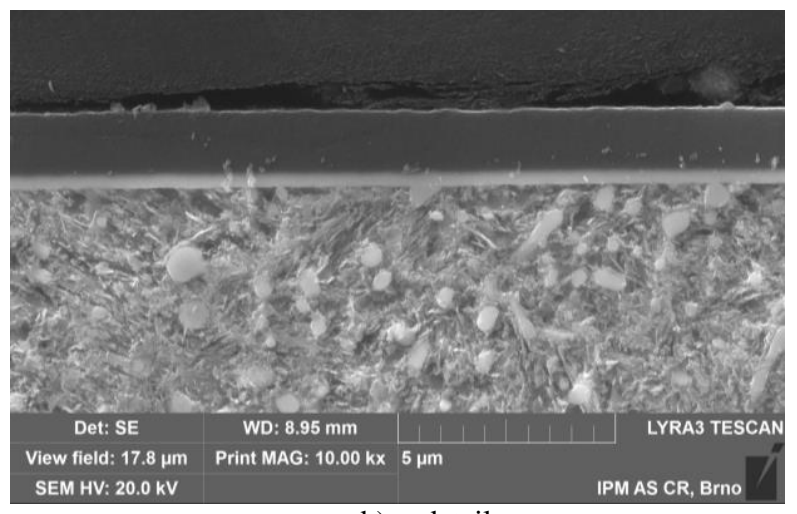

b) detail

Fig. 7. CarbonX coating, etch. $0.5 \%$ Nital, SEM

\section{Summary and conclusion}

The obtained results show that friction coefficient of $100 \mathrm{Cr} 6$ steel against steel has been successfully reduced. The result was achieved with a CarbonX coating applied to this steel. Friction coefficient value of $100 \mathrm{Cr} 6$ bearing steel against steel was on average $\mu=0.8(-)$. The friction coefficient of this pair was reduced 3 times after the coating was created. Average friction coefficient value of the coating against steel was $\mu=0.25$ (-). These results were obtained in the absence of lubricant under dry friction conditions.

The coating temperature $\left(240^{\circ} \mathrm{C}\right)$ does not significantly affect substrate of the material. The substrate hardness was reduced by $4 \mathrm{HRC}$. The measured hardness of the $59 \mathrm{HRC}$ substrate meets normative conditions for bearing steel.

CarbonX thin DLC coating formed on the surface of quenched 100Cr6 bearing steel significantly improves friction properties of this steel.

\section{Acknowledgements}

This work was supported under the project of Operational Programme Research and Innovation: Research and development activiries of the University of Zilina in the Industry of 21st century in the field of materials and nanotechnologies, No. 313011T426. The project is co-funding by European Regional Development Fund and Implementation of Integrated GPS System for Specification and Products Verification into the Teaching Process of Engineering Study Programs and Putting them into the Technical Practice, Nr. KEGA 026ŽU-4/2019.

\section{Reference}

Brezničan, M., Fabian, P., Meško, J., Drbúl, M., 2013. The simulation of influence of quenching temperature on properties of bearing rings. Manufacturing technology: journal for science, research and production, $13,20-25$.

Drabik, M., Truchly, M., Ballo, V., et al., 2018. Influence of substrate material and its plasma pretreatment on adhesion and properties of WC/a-C:H nanocomposite coatings deposited at low temperature, Surface and coatings technology, 333, 138-147.

Fabian, P., Meško, J., Nikolič, R., 2017. Simulation of quenching process of steels creating complex carbides, FME transactions, 45, 510-516.

Holleck, H., Schier, V., 1995. Multilayer PVD coatings for wear protection. Surf. Coat. Technol. 76, 328-336.

Liščić, B., Tensi, H.M., Canale, L.C.F., Totten, G.E., 2010. Quenching theory and technology, $2^{\text {nd }}$ ed., CRC Pres, Taylor and Francis Group, Boca Raton, New York, USA.

Pastorek, F., Borko, K., Fintová, S., Kajánek, D., Hadzima, B., 2016. Effect of surface pretreatment on quality and electrochemical corrosion properties of manganese phosphate on S355J2 HSLA steel. Coatings, 6 (4), 9.

Radek, N., Szczotok, A., Gadek-Moszczak, A., el al., 2018. The impact of laser processing parameters on the properties of electro-spark deposited coatings, Archives of metallurgy and materials, 63, 809-816.

Tsui, L.-K., Garzon, F., 2017. CarbonXS GUI: A graphical front-end for CarbonXS. J. Appl. Crystallogr. 50, 1830-1833.

Vicen, M., Fabian, P., Bronček, J., Radek, N., 2019. Effect of PVD coating on change properties of 100Cr6 bearing steel, Slovak Journal of Technolog, 11, 63-66.

Ulewicz, R., Mazur, M., 2013. Fatigue testing structural steel as a factor of safety of technical facilities maintenance. Production Engineering $\mathrm{Ar}$ chives, 1(1), 32-34.

\section{$100 \operatorname{Cr} 6$ 钢上的CarbonX涂层的摩擦学性能研究}

\section{關鍵詞 \\ 摩擦学 \\ DLC涂层 \\ $100 \mathrm{Cr} 6$ 钢 \\ 摩擦}

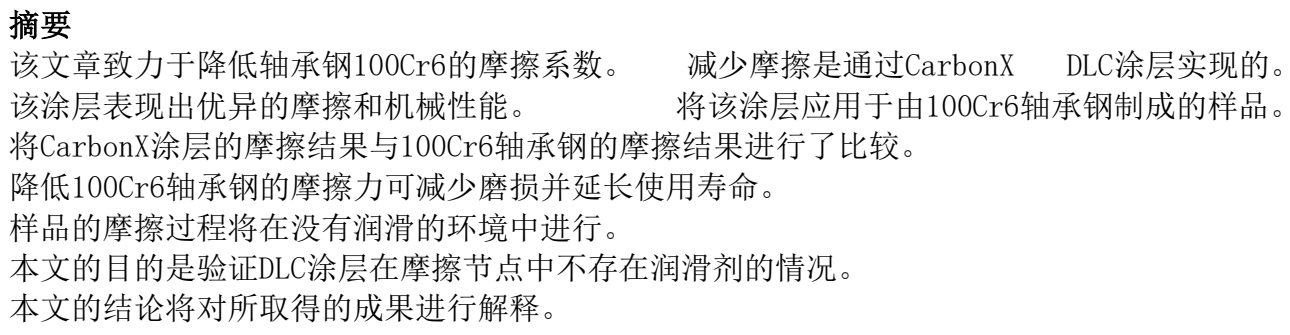

